\title{
openheart Interhospital and interindividual variability in secondary prevention: a comparison of outpatients with a history of chronic coronary syndrome versus outpatients with a history of acute coronary syndrome (the iASPIRE Study)
}

\author{
James MG Curneen (10 , ${ }^{1}$ Conor Judge, ${ }^{2,3}$ Bryan Traynor, ${ }^{4}$ Anthony Buckley, ${ }^{5}$ \\ Lavanya Saiva, ${ }^{6}$ Laura Murphy, ${ }^{7}$ Donal Murray, ${ }^{8}$ Sean Fleming, ${ }^{9}$ Peter Kearney, ${ }^{10}$ \\ Ross T Murphy, ${ }^{11}$ Godfrey Aleong, ${ }^{4}$ Thomas J Kiernan, ${ }^{5}$ James O'Neill, ${ }^{6}$ \\ David Moore, ${ }^{7}$ Bridog Nicaodhabhui, ${ }^{2,12}$ John Birrane, ${ }^{2,12}$ Patricia Hall, ${ }^{12}$ \\ James Crowley, ${ }^{12}$ Irene Gibson, ${ }^{12}$ Catriona S Jennings (D) ,12 David Wood, ${ }^{12}$ \\ Kornelia Kotseva, ${ }^{12}$ John William McEvoy (D) ${ }^{12}$
}

To cite: Curneen JMG, Judge C, Traynor B, et al. Interhospital and interindividual variability in secondary prevention: a comparison of outpatients with a history of chronic coronary syndrome versus outpatients with a history of acute coronary syndrome (the iASPIRE Study). Open Heart 2021;8:e001659. doi:10.1136/

openhrt-2021-001659

KK and JWM contributed equally.

Received 23 March 2021 Accepted 31 May 2021

Check for updates

(C) Author(s) (or their employer(s)) 2021. Re-use permitted under CC BY-NC. No commercial re-use. See rights and permissions. Published by BMJ.

For numbered affiliations see end of article.

Correspondence to

Professor John William McEvoy; johnwilliam.mcevoy@nuigalway. ie

\section{ABSTRACT}

Background Studying variability in the care provided to secondary prevention coronary heart disease (CHD) outpatients can identify interventions to improve their outcomes.

Methods We studied outpatients who had an index CHD event in the preceding 6-24 months. Eligible CHD events included acute coronary syndrome (ACS) and coronary revascularisation for stable chronic coronary syndrome (CCS). Site training was provided by a core team and data were collected using standardised methods.

Results Between 2017 and 2019, we enrolled 721 outpatients at nine Irish study sites; $81 \%$ were men and mean age was 63.9 (SD \pm 8.9 ) years. The study examination occurred a median of 1.16 years after the index CHD event, which was ACS in 399 participants (55\%) and stable-CCS in 322 . On examination, $42.5 \%$ had blood pressure (BP) >140/90 mm Hg, 63.7\% had lowdensity lipoprotein cholesterol (LDL-C) $>1.8 \mathrm{mmol} / \mathrm{L}$ and $44.1 \%$ of known diabetics had an $\mathrm{HbA} 1 \mathrm{c}>7 \%$. There was marked variability in risk factor control, both by study site and, in particular, by index presentation type. For example, $82 \%$ of outpatients with prior-ACS had attended cardiac rehabilitation versus $59 \%$ outpatients with prior-CCS $(p<0.001)$ and there were also large differences in control of traditional risk factors like LDL-C $(p=0.002)$ and systolic BP $(p<0.001)$ among outpatients with prior-ACS versus prior-CCS as the index presentation.

Conclusions Despite international secondary prevention guidelines broadly recommending the same risk factor targets for all adults with $\mathrm{CHD}$, we found marked differences in outpatient risk factor control and management on the basis of hospital location and index CHD presentation type (acute vs chronic). These findings highlight the need to reduce hospital-level and patientlevel variability in preventive care to improve outcomes; a

\section{Key questions}

What is already known about this subject?

- The ASPIRE-3-PREVENT and EUROASPIRE studies demonstrated inadequate management of patients following a diagnosis of coronary heart disease (CHD), through risk factor and lifestyle modification, cardiac rehabilitation and medication adherence.

- However, the interhospital and interindividual variability in secondary preventive care is less well understood, with few observational studies performed.

What does this study add?

- Here we describe marked variability in postdischarge CHD secondary prevention care on the basis of index presentation type (acute vs chronic coronary syndrome).

- Interhospital variability in postdischarge secondary preventive care at the national level is also strongly evident, pointing to systems-level deficiencies in care.

How might this impact on clinical practice?

Our research reveals the urgent need for countries to adopt national prevention programmes for CHD that can monitor both patient-level and institutionlevel variability in preventive care and for replicative studies across Europe in preventive cardiology.

lesson that should inform CHD prevention programmes in Ireland and around the world.

\section{INTRODUCTION}

Coronary heart disease (CHD) remains one of the leading causes of morbidity and mortality 
around the world. ${ }^{12}$ Secondary prevention is an important strategy to reduce the risk of recurrent CHD. ${ }^{3}{ }^{4}$ For example, cardiac rehabilitation (CR) is proven to reduce future hospitalisations and improve cardiovascular mortality and quality of life among adults with $\mathrm{CHD} .{ }^{5-7}$ Clinical practice guidelines recommend a coordinated set of actions at the population, health-system and individual levels to optimise risk factors among persons with established CHD. ${ }^{8-10}$ Importantly, guideline-recommended risk factor targets for secondary prevention do not differ on the basis of whether the index CHD event was acute or chronic in nature.

The EUROASPIRE (EUROpean Action on Secondary and Primary prevention by Intervention to Reduce Events) surveys have studied the implementation of the European Society of Cardiology (ESC) guidelines on secondary CHD prevention among outpatients with an index CHD event withing the previous 6-24 months. The most recent survey, EUROASPIRE V, demonstrated a persistent deficit in preventive care. ${ }^{11}$ However, prior EUROASPIRE surveys have not studied differences in secondary prevention on the basis of index CHD presentation type, nor have prior EUROASPIRE surveys studied interhospital variability in outpatient care. This is important because interhospital variability in preventive medications at discharge has been identified in US cohorts as a target for intervention to improve outcomes in these patients. ${ }^{12}{ }^{13}$ However, data on interhospital variability in postdischarge outpatient preventive care quality are lacking, as is information on whether the intensity of secondary prevention provided to European outpatients differs by CHD presentation type.

Based on the EUROASPIRE study design, the iASPIRE (Irish Action on Secondary and Primary prevention by Intervention to Reduce Events) study is the first multicentre, national, in-person epidemiologic examination of secondary CHD prevention conducted in Ireland. In this analysis, we compared differences in preventive care targets, both in our study sample overall and according to either the hospital site or the type of CHD at the index presentation (ie, acute coronary syndrome (ACS) or chronic coronary syndrome (CCS)).

\section{METHODS}

\section{Geographical areas and sampling frame}

The iASPIRE study was a cross-sectional survey coordinated by the Irish National Institute for Prevention and Cardiovascular Health (NIPC) and was conducted during 2017-2019. Patients were recruited from nine hospital sites that were geographically dispersed across Ireland (figure 1). Four of these centres were primary percutaneous coronary intervention (PCI) centres, with a catchment area of both rural and urban patient populations. Five centres did not have access to a 24-hour cardiac catheterisation lab, with ST elevation myocardial infarction (MI) patients who present to these centres being transferred to primary PCI centres for angiography and intervention, before repatriation and ongoing medical and preventive care typically being provided by the initial admission hospital. Some, but not all, of the five nonprimary PCI centres had access to a diagnostic cardiac catheterisation lab but none to PCI. The lead investigator at each study site obtained local ethics committee approval and all participating patients provided written informed consent.

\section{Study population}

Patients eligible for inclusion were men and women aged greater than 18 years and less than 80 years with a first or recurrent diagnosis of CHD at least 6 months from and at most 24 months prior to enrollment. The index diagnosis of CHD was based on either a history of elective coronary artery bypass graft (CABG), elective percutaneous transluminal coronary angioplasty (PTCA), acute myocardial ischaemia/unstable angina without evidence of MI or acute MI (ST elevation or non-ST elevation MI). The former two forms of index presentation were considered stable-CCS ${ }^{10}$ and the latter two forms of index presentation were categorised at ACS. We use the term 'stable-CCS' rather than 'CCS' to indicate that these patients all had stable ischaemic heart disease at the time of their index CHD presentation (noting that some cardiologists may consider a patient with a history of ACS at the index presentation an average of 1 year previously to now be in the CCS phase of their illness when attending for the iASPIRE study examination).

\section{Data collection and definitions}

Recruitment at each hospital site was by local teams, typically consisting of nurses (or other allied health professionals) and the local consultant cardiologist or cardiology service. Training of staff at each study site was performed by the central coordinating research team at NIPC. Each site was asked to create a register of patients eligible for recruitment based on the clinical admission code and admission date, with patients identified retrospectively based on their consecutive presentation from outpatient clinics, coronary care unit records or local CR service records. All patients meeting the inclusion criteria were contacted by phone and post by the local coordinating team and provided with an invitation to participate, patient information leaflet and informed consent form.

For the present analysis, and in keeping with the EUROASPIRE design, data were collected from two timepoints; (a) from the index CHD event using medical records, and (b) at the baseline in-person interview and examination that occurred 6-24 months after the index CHD event. The latter time-point was chosen to give patients and the health-system sufficient time to achieve guideline-recommended secondary prevention targets. Confirmation of attendance at the in-person interview and examination was obtained prior to medical chart review of the index event. 


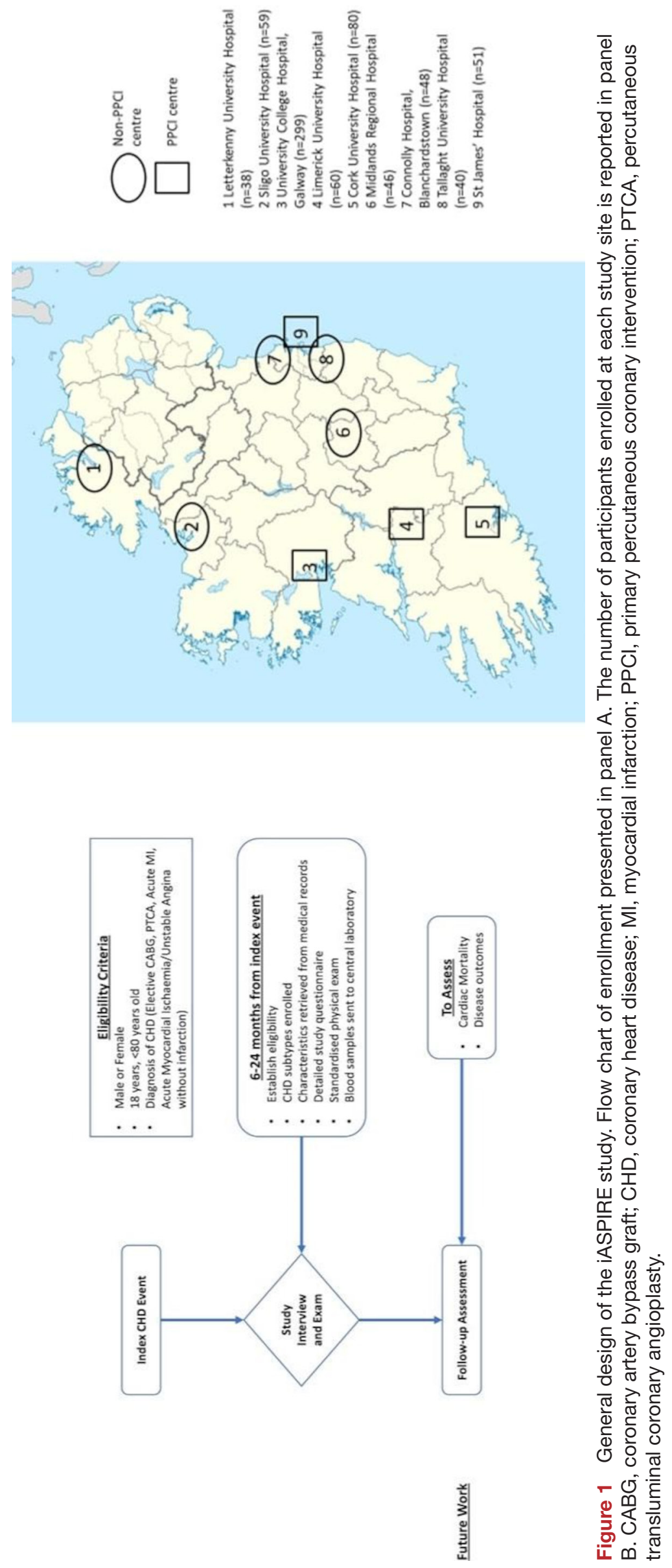


Therefore, all those who agreed to participate had their height, weight, waist circumference, history of hypertension, dyslipidaemia and heart failure, smoking status, aspirin and statin usage, socioeconomic factors and other parameters documented from medical records of the index CHD hospitalisation (consequently these variables represent retrospectively collected data). Participants then attended an in-person study interview and examination using standardised methods and instruments. Study-specific case report forms were used to collect data, including height, weight, waist circumference, smoking status, cholesterol levels, blood pressure (BP) and diabetic control/undiagnosed diabetes. Interviewees were assessed for self-reported exercise and dietary changes. Therapeutic interventions in the form of BP-lowering medications, antiplatelets, lipid-lowering drugs and smoking cessation therapies were also recorded at the interview.

Measurement of height and weight at the study examination was conducted in light indoor clothes without shoes using SECA scales 701 and a measuring stick (model 220). Waist circumference was measured using a metal tape horizontally in the mid-axillary line midway between the lowest rim of the rib cage and tip of the iliac crest with the patient standing. Smoking status was determined by self-reported smoking and/or a breath carbon monoxide exceeding $10 \mathrm{ppm}$ using a Smokerlyzer in all participants. ${ }^{14}$ Targets for physical activity were assessed using the question 'How often do you engage in any regular activity long enough to work up a sweat/heart beats rapidly?' BP measurement was performed two times on the right upper arm while sitting, using an automatic digital sphygmomanometer (Omron M6 (HEM 7211-E)) and the mean of the two measurements was used in the data analyses. Variables collected during this study were comprehensive and reflective of the secondary prevention targets described in the 2016 European guidelines on cardiovascular disease (CVD) prevention in clinical practice. ${ }^{8}$ Statin intensity was defined by the American College of Cardiology/American Heart Association Task Force Guidelines. ${ }^{15}$

Venous blood samples were drawn from participants, processed, frozen locally at $-70^{\circ} \mathrm{C}$ and sent to the Central laboratory (National Institute for Health and Welfare in Helsinki, Finland) for measurements of total cholesterol, high-density lipoprotein (HDL)-cholesterol, triglycerides and haemoglobin A1c (HbA1c). The laboratory is accredited by the Finnish Accreditation Service and meets the requirements of the SFS-EN ISO/IEC 17025:2005. The low-density lipoprotein cholesterol (LDL-C) was calculated by Friedewald's formula. ${ }^{16}$ Fasting plasma glucose (FPG) was also obtained during the study visit using capillary glucometers (HemoCue). Undiagnosed diabetes was determined using HbAlc $(\geq 6.5 \%)$ and/or FPG $(\geq 7 \mathrm{mmol} / \mathrm{L})$.

\section{Data management}

Electronically collected data were anonymised, encrypted and submitted online to the data management centre (EURObservational Research Programme, Sophia Antipolis, France).

\section{Statistical analyses}

Stable-CCS was defined as patients who presented electively for revascularisation of ischaemic heart disease with CABG or PTCA. ACS was defined as those presenting with acute myocardial ischaemia or infarction, based on the clinical impression of the treatment team on discharge. The main outcome measures were the proportions of coronary patients achieving the lifestyle, risk factor and therapeutic targets as defined in the 2016 European guidelines on CVD prevention. ${ }^{8}$ Based on prior EUROASPIRE survey results, ${ }^{11}$ we assumed a baseline prevalence of poor risk factor control of between $40 \%$ and $60 \%$ and consequently estimated that 350 participants in the ACS group and 350 participants in the stable-CCS group (700 in total) would be necessary to discern a difference in risk factor prevalence of $10 \%$ or more between these two groups, with a 5\% level of significance and power of $80 \%$. Descriptive statistics of the patient sample and outcomes were reported in the overall study sample and further subdivided by CHD presentation type or by sex category. Differences between groups were assessed using Student's t-test for normally distributed continuous variables or the $\chi^{2}$ test for categorical variables. In the cases of non-normal distributions, non-parametric testing was used. Site variability in outcomes was also described. Analyses were conducted using R V.4.0.2 and a two-sided $\mathrm{p}$ value of $<0.05$ was chosen as the cut-off for statistical significance.

\section{RESULTS}

We enrolled 721 participants from nine sites; the participant's mean age was 63.9 years $( \pm$ SD 8.9$)$ and $586(81 \%)$ were men. The breakdown of participant numbers by site is provided in figure $1 \mathrm{~b}$. The total numbers of participants with ACS $(n=322,45 \%)$ versus stable-CCS $(n=399$, $55 \%$ ), as their index CHD presentation, were similar. The median time from the index CHD event to the patient's consent for baseline study examination was 1.16 years (IQR 0.87-1.55 years).

\section{Demographics and cardiovascular risk factors at the time of the index CHD event}

The socioeconomic characteristics, cardiac risk factor status and relevant baseline medications of all participants at the time of their index event are summarised in table 1. A comparison is also provided according to the type of index event (ACS vs stable-CCS) and according to sex. These variables were all collected from the medical record of the index CHD presentation, with the exception of some variables missing from the medical record that were collected at the study interview and that were deemed unlikely to have changed in the interim since the index presentation (ie, level of education, marriage status, family income).

Almost half of participants were known to have a history of hypertension and dyslipidaemia prior to their index CHD presentation (with the prevalence of both 
Cardiac risk factors and prevention

Table 1 Characteristics of the iASPIRE population (at/before the index CHD presentation)

\begin{tabular}{|c|c|c|c|c|c|c|c|}
\hline & \multirow{2}{*}{$\begin{array}{l}\text { CHD outpatient } \\
\text { sample overall } \\
n=721\end{array}$} & \multirow{2}{*}{$\begin{array}{l}\text { History of } \\
\text { stable CCS } \\
n=322 \\
\end{array}$} & \multirow{2}{*}{$\begin{array}{l}\text { History of } \\
\text { ACS } \\
n=399 \\
\end{array}$} & \multirow[b]{2}{*}{$P$ value } & \multirow{2}{*}{$\begin{array}{l}\text { Male } \\
n=586\end{array}$} & \multirow{2}{*}{$\begin{array}{l}\text { Female } \\
n=135\end{array}$} & \multirow[b]{2}{*}{$P$ value } \\
\hline & & & & & & & \\
\hline Sex, n (\%) & & & & 0.233 & & & $<0.001$ \\
\hline Male & $586(81.3)$ & $255(79.2)$ & $331(83.0)$ & & $586(100)$ & $0(0.00)$ & \\
\hline $\begin{array}{l}\text { Waist circumference, } \\
\mathrm{cm} \text {, mean (SD) }\end{array}$ & $95.3(9.41)$ & $97.5(9.48)$ & $87.8(4.60)$ & 0.115 & $97.2(8.12)$ & $91.5(12.5)$ & 0.523 \\
\hline $\begin{array}{l}\text { History of hypertension } \\
\text { prior to index event, } \\
\mathrm{n}(\%)\end{array}$ & $349(48.4)$ & $166(51.6)$ & $183(45.9)$ & $<0.001$ & $280(47.8)$ & $69(51.1)$ & 0.518 \\
\hline $\begin{array}{l}\text { History of diabetes } \\
\text { prior to index event, } \\
\mathrm{n}(\%)\end{array}$ & 72 (9.99) & $43(13.4)$ & $29(7.27)$ & $<0.001$ & 60 (10.2) & $12(8.89)$ & 0.335 \\
\hline $\begin{array}{l}\text { History of heart failure } \\
\text { prior to index event, } \\
\mathrm{n}(\%)\end{array}$ & $50(6.93)$ & 37 (11.5) & $13(3.26)$ & $<0.001$ & $40(6.83)$ & $10(7.41)$ & 0.429 \\
\hline $\begin{array}{l}\text { Smoking status prior to } \\
\text { index event, } \mathrm{n}(\%)\end{array}$ & & & & $<0.001$ & & & 0.242 \\
\hline Never smoker & $136(18.9)$ & 47 (14.6) & 89 (22.3) & & $106(18.1)$ & $30(22.2)$ & \\
\hline $\begin{array}{l}\text { Non-smoker (but } \\
\text { previous smoking } \\
\text { history unknown) }\end{array}$ & $59(8.18)$ & 27 (8.39) & $32(8.02)$ & & $46(7.85)$ & $13(9.63)$ & \\
\hline $\begin{array}{l}\text { Highest level of } \\
\text { education }\end{array}$ & & & & 0.101 & & & 0.118 \\
\hline No formal schooling & $3(0.42)$ & $2(0.62)$ & $1(0.25)$ & & $2(0.34)$ & $1(0.74)$ & \\
\hline $\begin{array}{l}\text { Less than primary } \\
\text { school }\end{array}$ & $16(2.22)$ & $8(2.48)$ & $8(2.01)$ & & $10(1.71)$ & $6(4.44)$ & \\
\hline $\begin{array}{l}\text { Primary school } \\
\text { completed }\end{array}$ & $268(37.2)$ & $137(42.5)$ & $131(32.8)$ & & $225(38.4)$ & $43(31.9)$ & \\
\hline $\begin{array}{l}\text { Secondary school/ } \\
\text { high school/ } \\
\text { intermediate training }\end{array}$ & $280(38.8)$ & $114(35.4)$ & $166(41.6)$ & & $223(38.1)$ & $57(42.2)$ & \\
\hline $\begin{array}{l}\text { College/university/ } \\
\text { postgraduate } \\
\text { completed }\end{array}$ & $149(20.7)$ & $60(18.6)$ & $89(22.3)$ & & $123(21.0)$ & 26 (19.3) & \\
\hline $\begin{array}{l}\text { Relationship status, } \\
\text { n (\%) }\end{array}$ & & & & 0.024 & & & $<0.001$ \\
\hline Married & $517(71.7)$ & $217(67.4)$ & 300 (75.2) & & $433(73.9)$ & $84(62.2)$ & \\
\hline Divorced/separated & $83(11.5)$ & $38(11.8)$ & $45(11.3)$ & & $61(10.4)$ & $22(16.3)$ & \\
\hline Widow/widower & $48(6.66)$ & $29(9.01)$ & $19(4.76)$ & & $26(4.44)$ & $22(16.3)$ & \\
\hline Never been married & $55(7.63)$ & $31(9.63)$ & $24(6.02)$ & & $51(8.70)$ & $4(2.96)$ & \\
\hline
\end{tabular}


Table 1 Continued

\begin{tabular}{|c|c|c|c|c|c|c|c|}
\hline & $\begin{array}{l}\text { CHD outpatient } \\
\text { sample overall }\end{array}$ & $\begin{array}{l}\text { History of } \\
\text { stable CCS }\end{array}$ & $\begin{array}{l}\text { History of } \\
\text { ACS }\end{array}$ & & Male & Female & \\
\hline & $n=721$ & $\mathrm{n}=322$ & $\mathrm{n}=399$ & $P$ value & $\mathrm{n}=586$ & $n=135$ & $P$ value \\
\hline Living alone, $\mathrm{n}(\%)$ & $116(16.1)$ & $62(19.3)$ & $54(13.5)$ & 0.115 & $88(15.0)$ & $28(20.7)$ & 0.22 \\
\hline Family income, n (\%) & & & & 0.045 & & & 0.221 \\
\hline Very low & $40(5.55)$ & $19(5.90)$ & $21(5.26)$ & & $34(5.80)$ & $6(4.44)$ & \\
\hline Low & $171(23.7)$ & $93(28.9)$ & 78 (19.5) & & $147(25.1)$ & $24(17.8)$ & \\
\hline Middle & $451(62.6)$ & $188(58.4)$ & $263(65.9)$ & & $355(60.6)$ & $96(71.1)$ & \\
\hline High & $34(4.72)$ & $12(3.73)$ & $22(5.51)$ & & $30(5.12)$ & $4(2.96)$ & \\
\hline
\end{tabular}

ACS, acute coronary syndrome; CCS, chronic coronary syndrome; CHD, coronary heart disease.

conditions being higher among those presenting with a stable-CCS event, $\mathrm{p}<0.001)$. Diabetes prior to the index event was reported in $10 \%$ of participants (again with higher rates among persons with stable-CCS compared with ACS presentations). Almost one-sixth reported a current history of smoking at the time of their index presentation, while approximately two-fifths were former smokers. One-third of participants reported very low or low family income.

Under half of the sample population reported taking aspirin prior to their index event, with only two-fifths taking statin therapy. A statistically significant association was observed between index event and both aspirin and statin therapy ( $p$ value $<0.001$ ), with a large difference in those taking aspirin therapy between the two groups prior to admission (61.5\% CCS vs $33.6 \%$ ACS).

\section{Cardiac rehabilitation}

Overall, 608 patients (84.3\%) reported being advised to attend CR during their index presentation. Adherence to CR was not optimal; however, with just 516 participants reporting that they attended more than half the sessions (71.6\% of all patients). A higher proportion of patients with ACS were advised to attend CR $(90.5 \%)$ and also attended more than half of the sessions $(81.7 \%)$, compared with those with stable-CCS as their index presentation $(76.7 \%$ and $59 \%$, respectively, $\mathrm{p}<0.001)$. There were no sex differences in CR referrals or attendance.

\section{Control of lifestyle risk factors at the study interview (approx. 1 year after the index event)}

Over one-third of participants reported at the study interview that they never participated in regular exercise of any kind (table 2). The majority reported that they reduced their salt, fat, calorie and sugar intake and increased their fruit, vegetables and fish intake following the index CHD event. While one-quarter of participants self-reported weight loss between the index event and the baseline examination, the objectively recorded mean weight of participants was marginally increased at the time of the study interview $(85.8 \mathrm{~kg})$ compared with the index event $(85.5 \mathrm{~kg})$. Over four-fifths of the sample population were either overweight or obese at the time of the study examination, with nearly half of these obese. Over half also displayed central obesity at the study exam. Men were more commonly overweight $(86.5 \%$ vs $74.1 \%$, p value $0.002)$, whereas central obesity was more common in women $(49.2 \%$ vs $63.7 \%$, p value 0.002$)$.

\section{Control of medical risk factors at the study interview}

Over one-third of participants reported no use of BP-lowering therapies at the time of interview (table 3). Nearly $40 \%$ of subjects were not taking an ARB or ACE-inhibitor, while almost one-third were not on a beta blocker. There was a statistically significant association between the index CHD event type and the prevalence of ACE-inhibitor use at the study interview, with a lower rate observed in those with stable-CCS presentations. This difference was also present for statin therapy $(84.5 \%$ use among ACS vs $74.2 \%$ among persons with stable-CCS as the index CHD event, $\mathrm{p}<0.001$ ). Overall, only $58.4 \%$ of participants were on high-intensity statins at the interview. Finally, though the use of smoking cessation therapies was very low, there was a significant difference in the rate of nicotine replacement therapy $(\mathrm{p}=0.011)$ between patients with stable-CCS (17 out of 28 ) versus ACS (39 out of 69 ) who were known to be current smokers at the time of their index event. Only $54 \%$ of study participants reported receiving the influenza vaccination in the year since their index CHD event.

Concordant with our findings on preventive therapies, notable deficiencies were also documented in the attainment of guideline-recommended risk factor targets among the study sample. The mean LDL-C for participants at the time of the iASPIRE study visit was $2.05 \mathrm{mmol} / \mathrm{L}$, with a statistically significant difference between mean LDL-C levels achieved according to the type of index CHD presentation (table 4). Only 36.3\% of participants met the LDL-C target of $<1.8 \mathrm{mmol} / \mathrm{L}$ $(<100 \mathrm{mg} / \mathrm{dL})$ at interview and only $13 \%$ met an LDL-C goal of $<1.4 \mathrm{mmol} / \mathrm{L}$. Similarly, just $57 \%$ of participants met a BP goal of less than $140 / 90 \mathrm{~mm} \mathrm{Hg}$, with $72 \%$ having BPs higher than 130/80 mm Hg. BP control was better in the ACS compared with the stable-CCS group. Undiagnosed diabetes was uncovered in $32(12.9 \%)$ participants without known diabetes at the study visit and, among those with known diabetes at the time of their index CHD 
Table 2 Lifestyle interventions at study interview (approximately 1 year after the index event)

\begin{tabular}{|c|c|c|c|c|}
\hline & $\begin{array}{l}\text { CHD outpatient } \\
\text { sample overall }\end{array}$ & $\begin{array}{l}\text { History of } \\
\text { stable CCS }\end{array}$ & $\begin{array}{l}\text { History of } \\
\text { ACS }\end{array}$ & \\
\hline & $\mathrm{n}=721$ & $\mathrm{n}=322$ & $\mathrm{n}=399$ & $P$ value \\
\hline Regular exercise, $\mathrm{n}(\%)$ & $449(62.3)$ & $194(60.2)$ & $255(63.9)$ & 0.351 \\
\hline $\begin{array}{l}\text { How often do you engage in any regular activity long enough to } \\
\text { work up a sweat? (heart beats rapidly), } \mathrm{n}(\%)\end{array}$ & & & & 0.14 \\
\hline Sometimes & $201(27.9)$ & $92(28.6)$ & $109(27.3)$ & \\
\hline Never/rarely & $241(33.4)$ & $118(36.6)$ & $123(30.8)$ & \\
\hline Self-reported dietary changes (since index event) & & & & \\
\hline Reduction of salt intake, $\mathrm{n}(\%)$ & $543(75.3)$ & $234(72.7)$ & $309(77.4)$ & 0.321 \\
\hline Eating more fruit and vegetables, $\mathrm{n}(\%)$ & $605(83.9)$ & $267(82.9)$ & $338(84.7)$ & 0.675 \\
\hline Eating more fish, n (\%) & $544(75.5)$ & $236(73.3)$ & $308(77.2)$ & 0.472 \\
\hline Weight & & & & \\
\hline Self-reported weight loss, n (\%) & $193(26.8)$ & $80(24.8)$ & $113(28.3)$ & 0.124 \\
\hline $\mathrm{BMI}, \mathrm{kg} / \mathrm{m}^{2}$, mean (SD) & $29.3(4.90)$ & $29.7(5.06)$ & $29.0(4.75)$ & 0.073 \\
\hline Prevalence of obesity (BMl=30), $n(\%)$ & $279(38.7)$ & $128(39.8)$ & $151(37.8)$ & 0.207 \\
\hline Prevalence of overweight subjects (BMI >25), $\mathrm{n}(\%)$ & $607(84.2)$ & $278(86.3)$ & $329(82.5)$ & 0.122 \\
\hline Waist circumference, $\mathrm{cm}$, mean (SD) & $100(13.7)$ & $101(14.3)$ & $99.2(13.1)$ & 0.029 \\
\hline $\begin{array}{l}\text { Prevalence of central obesity (WC }>88 \mathrm{~cm} \text { for women, }>102 \mathrm{~cm} \text { for } \\
\text { men) }\end{array}$ & $373(51.7)$ & $179(55.6)$ & $194(48.6)$ & 0.136 \\
\hline
\end{tabular}

ACS, acute coronary syndrome; BMI, body mass index; CCS, chronic coronary syndrome; CHD, coronary heart disease; WC, Waist circumference.

presentation, $44.1 \%$ had not achieved an HbA1c goal of $<7 \%$ by the study visit approximately 1 year later. Only $28.4 \%$ of participants reported self-monitoring of their $\mathrm{BP}$ at home and, among persons with known diabetes, only $76.5 \%$ self-monitoring their glucose levels. Finally, among participants who were current smokers at the time of their index event, $44.9 \%$ continued to smoke at the time of interview approximately 1 year later.

\section{Variability in results by study site}

Figure 2 shows a selection of the variability in preventive care and attainment of risk factor targets among the outpatients enrolled in our study across the nine hospital sites where recruitment occurred. Notably, a wide variability existed between hospital sites in attendance at CR sessions (delta 63\%). The use of beta-blocker and ACE-inhibitor therapy also differed widely depending on the site, ranging from a rate of $52 \%$ to $80 \%$ and $53 \%$ to $80 \%$, respectively. There was a high rate of anti-lipid drug usage across all sites, with less variability in this metric (the lowest rate was $74 \%$ but the majority of sites had rates $>90 \%$ ). However, the rate of hypertension (BP $\geq 140 / 90 \mathrm{~mm} \mathrm{Hg}$ ) noted on examination at the study visit was different between study sites, with a delta of $32 \%$. There was also inconsistency in advice on losing weight among those who were obese at baseline (between 17\% and $60 \%$ of those who were obese at the index presentation were never told to lose weight, delta $43 \%$ ). Finally, persistent smoking varied quite sharply across sites, ranging from $10 \%$ to $71 \%$ of those who were smoking at the time of their index event.

\section{DISCUSSION}

The iASPIRE study was conducted to provide a comprehensive understanding of the contemporary delivery of secondary preventive care to Irish patients with CHD and to identify areas for improvement that can be translated to both national and international levels. The main findings of the current iASPIRE study were that as many 
Table 3 Therapeutic interventions-at study interview (approximately 1 year after the index event)

\begin{tabular}{|c|c|c|c|c|}
\hline & $\begin{array}{l}\text { CHD outpatient } \\
\text { sample overall }\end{array}$ & $\begin{array}{l}\text { History of } \\
\text { stable CCS }\end{array}$ & $\begin{array}{l}\text { History of } \\
\text { ACS }\end{array}$ & \\
\hline & $n=721$ & $\mathrm{n}=322$ & $\mathrm{n}=399$ & $P$ value \\
\hline \multicolumn{5}{|l|}{ Blood pressure-lowering medications } \\
\hline Use of blood pressure-lowering drugs, $n(\%)$ & $449(62.3)$ & $199(61.8)$ & $250(62.7)$ & 0.978 \\
\hline Beta blocker, $\mathrm{n}(\%)$ & $488(67.7)$ & $207(64.3)$ & $281(70.4)$ & 0.146 \\
\hline ACEi, n (\%) & $317(45.9)$ & $115(37.8)$ & $202(52.2)$ & $<0.001$ \\
\hline ARB, n (\%) & $102(14.1)$ & $38(11.8)$ & $64(16.0)$ & 0.058 \\
\hline CCB, n (\%) & $110(15.3)$ & $46(14.3)$ & $64(16.0)$ & 0.151 \\
\hline Diuretics, $n(\%)$ & $74(10.3)$ & $32(9.94)$ & $42(10.5)$ & 0.223 \\
\hline \multicolumn{5}{|l|}{ Antiplatelets } \\
\hline Use of aspirin or other antiplatelets, $n(\%)$ & $673(93.3)$ & $296(91.9)$ & $377(94.5)$ & 0.377 \\
\hline \multicolumn{5}{|l|}{ Lipid-lowering drugs } \\
\hline Statins, $n(\%)$ & $576(79.9)$ & $239(74.2)$ & $337(84.5)$ & 0.004 \\
\hline High intensity statin, $\mathrm{n}(\%)$ & $421(58.4)$ & $144(44.7)$ & $277(69.4)$ & $<0.001$ \\
\hline Fibrates, $n(\%)$ & $2(0.28)$ & $1(0.31)$ & $1(0.25)$ & 0.037 \\
\hline Combination, n (\%) & $18(2.50)$ & $8(2.48)$ & $10(2.51)$ & 0.011 \\
\hline \multicolumn{5}{|l|}{ Smoking cessation therapies } \\
\hline Attendance at smoking cessation clinic, $\mathrm{n}(\%)$ & $22(3.05)$ & $4(1.24)$ & $18(4.51)$ & 0.006 \\
\hline Nicotine replacement therapy, $\mathrm{n}(\%)$ & $56(7.77)$ & $17(5.28)$ & $39(9.77)$ & 0.011 \\
\hline Bupropion, n (\%) & $3(0.42)$ & $0(0.00)$ & $3(0.75)$ & 0.03 \\
\hline Varenicline, n (\%) & $3(0.42)$ & $1(0.31)$ & $2(0.50)$ & 0.103 \\
\hline Influenza vaccination, $n$ (\%) & $388(53.8)$ & $179(55.6)$ & $209(52.4)$ & 0.689 \\
\hline
\end{tabular}

$\mathrm{ACEi}$, angiotensin converting enzyme inhibitor; ACS, acute coronary syndrome; ARB, angiotensin receptor blocker; CCB, calcium channel blocker; CCS, chronic coronary syndrome; CHD, coronary heart disease.

as one out of every two CHD outpatients are not at ESC guideline-recommended lifestyle and risk factor targets and, most importantly, that a wide variability exists for preventive care according to CHD presentation type and across study sites. Given the epidemiologically rigorous and multicentre design of iASPIRE (including both non-primary PCI and primary PCI hospital sites), many of these contemporary findings are likely to be broadly translatable to other western nations.

Indeed, a major strength of this iASPIRE report is that it is, to our knowledge, one of the first examinations of variability in postdischarge outpatient preventive care and attainment of risk factor targets on the basis of CHD presentation type (ie, ACS vs stable-CCS). While it is clinically intuitive that stable-CCS patients undergoing revascularisation (often as day-case procedures) may be less likely to receive the same intensity of secondary prevention care than ACS patients who are admitted to the hospital for 48 hours or longer, the striking fact is that guidelines do not differ in the intensity of recommended secondary prevention risk factor targets for ACS versus stable-CCS patients. Therefore, according to most guidelines, all patients with known CHD should receive the same intensity of secondary prevention care, particularly as regards attainment of risk factor targets. Our data indicate that this is not the what happens in clinical practice, an inequity that has heretofore received little attention.

We found one prior study, by Ferrières $e t$ al, which also evaluated differences in preventive care on the basis of CHD presentation type. ${ }^{17}$ However, among those with ACS, the authors looked at differences in the intensity of secondary prevention medications at discharge from the hospital. By contrast, iASPIRE studied the intensity of secondary prevention among ACS and stable-CCS outpatients approximately a year after their index CHD presentation; which is sufficient time for the healthcare system to get these patients to recommended risk factor targets. Ferrières et al found similar disparities in prevention intensity at discharge on the basis of whether or not the patient had a history of ACS versus stable ischaemic heart disease (the older term for stable CCS). Our iASPIRE data add important information by showing that these disparities persist out to a year or more after discharge and are not corrected by the outpatient treatment team. Future studies from other countries will be of interest to confirm our findings.

Second, we found marked variability in outpatient preventive care and lifestyle/risk factor control across study hospital sites. While this type of variability has 
Cardiac risk factors and prevention

Table 4 Proportions of patients achieving the risk factor goals at study interview (approximately 1 year after the index event)

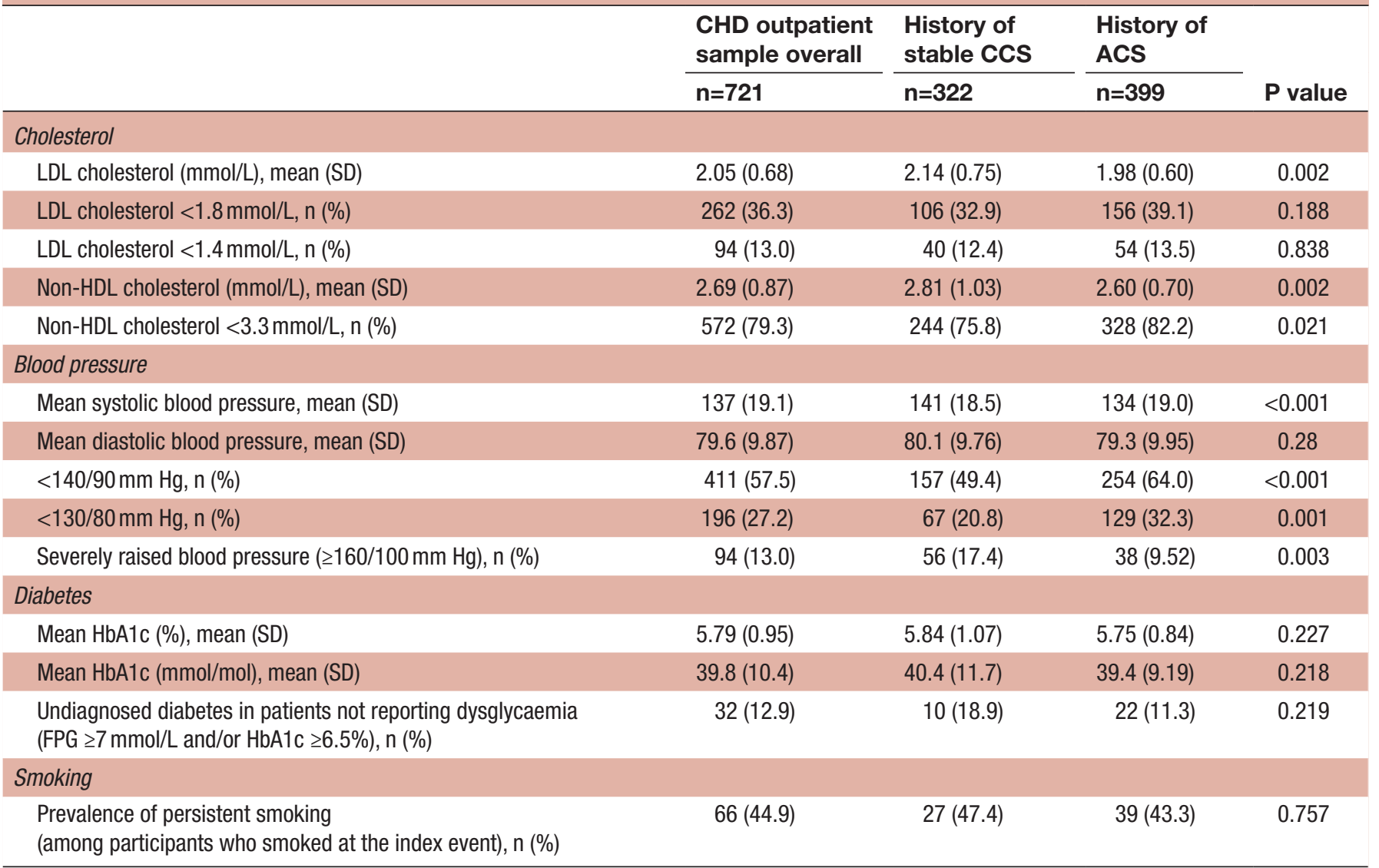

ACS, acute coronary syndrome; CCS, chronic coronary syndrome; CHD, coronary heart disease; FPG, fasting plasma glucose; HDL, highdensity lipoprotein; LDL, low-density lipoprotein.

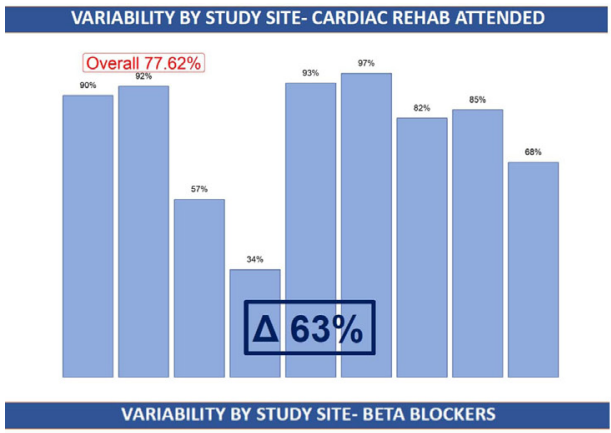

Overall $70.64 \%$

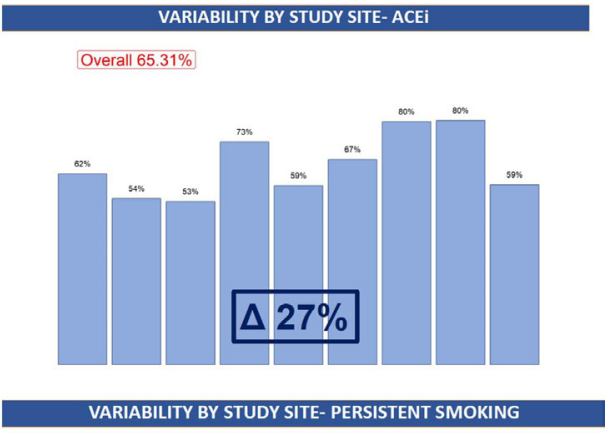

Overall $42.92 \%$
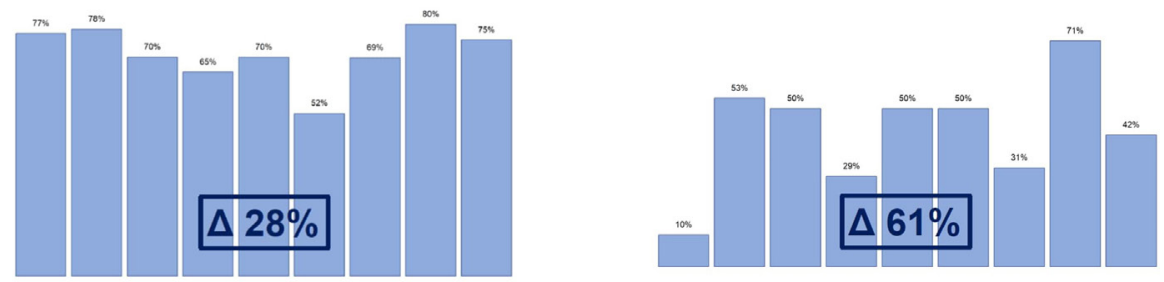

Figure 2 Variability in selected CHD prevention metrics across Irish study sites. The delta symbol in this figure reflects the difference between the site with the highest prevalence compared with the site with the lowest prevalence. The 'overall' means presented in red font in this figure are the means of the study site means. Hence, they may differ slightly from results presented in the tables (which are the means for the entire study sample). CHD, coronary heart disease. 
been described across countries and regions, ${ }^{18}$ we are not aware of studies looking at interhospital variability in the intensity of secondary CHD prevention care at the national-level. Therefore, by demonstrating marked variability in this regard, the iASPIRE study also demonstrates that opportunities exist to create national programmes designed to improve and standardise the delivery of outpatient preventive care across sites; both in Ireland and internationally. Indeed, by demonstrating marked variability across sites, this study provides a persuasive argument for national programmes designed to measure variability in preventive care in an effort to reduce disparities in care based on geography. In America, for example, the 'Get With The Guidelines' Registry aims to do just that; to measure and reduce variability across hospital sites in preventive care. However, the 'Get With The Guidelines' Registry evaluates interhospital variability in secondary preventive prescriptions at the time of discharge only, ${ }^{12}{ }^{13}$ whereas our iASPIRE data provide much needed information on interhospital variability in postdischarge preventive care and risk factor attainment among outpatients who are a year or more after their index event. Forthcoming secondary analyses of the iASPIRE study will evaluate results after stratifying the cohort on the basis of presentation to a primary PCI centre versus a non-primary PCI centre, which will provide further information on potential reasons for interhospital variability.

Third, this report has important implications for CVD prevention in Ireland. To our knowledge, the only prior national study of CHD secondary prevention in Ireland occurred as part of the landmark international Survey of Risk Factors (SURF) audit, which enrolled 1826 patients from 11 Irish sites in 2012-2013. ${ }^{19}$ However, SURF consisted of a brief one-page data-entry form and was completed by healthcare providers during nonstandarised clinic visits. Importantly, SURF also included patients with CHD irrespective of the time difference between their CHD diagnosis and the study date. Though SURF and iASPIRE cannot consequently be directly compared, both studies do provide an estimate of temporal change in CHD risk factors in Ireland (given SURF enrolled in 2012-2013 whereas iASPIRE enrolled in 2017-2019). The main differences in risk factor control between SURF and iASPIRE included attendance at CR, which appeared to increase from $66 \%$ in SURF to $85 \%$ in iASPIRE. The number of individuals with CHD who are overweight or obese appears to be increasing over time, from $80 \%$ to nearly $85 \%$. The number of participants with a controlled LDL $<1.8 \mathrm{mmol} / \mathrm{L}$ appears to have fallen from $46 \%$ in SURF to $38 \%$ in the more recent iASPIRE examination.

Some limitations of this study are also worth noting. First, it is observational in nature and there may have been selection bias (healthier and more informed CHD patients may have been more likely to enrol), though this would be expected to enrich the sample with more compliant patients and therefore the actual rates of risk factor attainment in the population may be worse than presented here. Second, results from the index presentation were obtained from the medical records and were therefore missing in some participants and not measured in a standardised way. However, the data from the study interview (approximately 1year later) were obtained in person using rigorous and standardised protocols. Third, we did not report information on recurrent events occurring after the index CHD presentation but before the interview, so it is possible a small minority of participants initially presenting with stable-CCS as the index admission may have had an unstable ACS event after the index admission but before the study interview 1year later. In addition, stable-CCS versus ACS was categorised based on clinical ascertainment, which may have led to some misclassification (though this is unlikely because the clinical definition of ACS is very well established and understood). Irrespective, both of these possibilities would bias comparisons between the groups towards the null; therefore, the significant differences found in our study are consequently expected to be valid. Fourth, our reliance on office BP measurements rather than ambulatory BP monitoring may be considered a minor limitation; however, our recording of $\mathrm{BP}$ was rigorous and used a standard operating procedure with uniform equipment. Fifth, we did not record an individual's left ventricular ejection fraction. Therefore, not all CHD participants would have a class 1 indication for beta-blocker and ACE-inhibitor medications because some may have had preserved ventricular function (though all would have at least a class 2 indication). Sixth, reported CR attendance in this study appeared to be higher compared with the EUROASPIRE counterparts and the previous SURF study. ${ }^{5}$ One explanation for this could be that our study sampling process included the review of records from both coronary care and CR units. Therefore, our CR attendance results likely demonstrate a best-case scenario. Seventh, due to a lack of the necessary infrastructure, primary and secondary prevention patients in Ireland rarely if ever have had prior cardiac CT with contrast (ie, non-invasive coronary angiography) and so we were unable to determine if the intensity of preventive therapies in this study was modified by this type of non-invasive information. Finally, eight, some of the between-site variability seen in this study may relate to variability in demographics by site; however, variability in other parameters like prescriptions for CR and standard secondary prevention medications can only be attributed to systems-level variability in care.

In conclusion, over half of CHD patients in Ireland are not at guideline-recommended lifestyle and risk factor targets approximately 1 year after the index event, outpatients with a history of stable-CCS presentations are often undertreated compared with those with a history of ACS (despite the recommended risk factor goals generally being the same in international guidelines), and there is also marked variability in outpatient preventive care across hospital sites. National prevention strategies that aim to reduce variability in prescribing and optimise prevention across sites, with a particular focus on outpatient care are urgently needed. This Irish experience can also provide direction to national secondary prevention coordinators elsewhere in their 
design and implementation of national CVD prevention programmes aimed at reducing variability in preventive care and optimising outcomes for all.

\section{Author affiliations}

${ }^{1}$ Clinical Pharmacology and Therapeutics, Galway University Hospital, Galway, Ireland

${ }^{2}$ Medicine, Galway University Hospital, Galway, Ireland

${ }^{3} \mathrm{HRB}$ Clinical Research Facility, National University of Ireland Galway, Galway, Ireland

${ }^{4}$ Cardiology, Letterkenny University Hospital, Letterkenny, Ireland

${ }^{5}$ Cardiology, University of Limerick Hospitals Group, Limerick, Ireland

${ }^{6}$ Cardiology, Connolly Hospital Blanchardstown, Blanchardstown, Ireland

${ }^{7}$ Cardiology, Tallaght University Hospital, Dublin, Ireland

${ }^{8}$ Cardiology, Sligo University Hospital, Sligo, Ireland

${ }^{9}$ Cardiology, Midland Regional Hospital Portlaoise, Portlaoise, Ireland

${ }^{10}$ Cardiology, Cork University Hospital, Cork, Ireland

${ }^{11}$ Cardiology, Saint James's Hospital, Dublin, Ireland

${ }^{12}$ National Institute for Prevention and Cardiovascular Health, National University of Ireland Galway, Galway, Ireland

\section{Twitter Laura Murphy @drLamurphy and John William McEvoy @johnwmcevoy}

Acknowledgements The authors thank Neil Johnson, Annie Hearn, Annie Costello, Agnieszka Adamska, Catriona Ahern, Maeve O'Reilly, Deirdre Mulvey, Aisling Mernin, Anne Reynolds, Kate Corrigan, Carol Ann Nugent, all participating patients, the teams at the HRB Clinical Research Facilities in Galway, Cork and St James', and the EORP for their important contributions to this study.

Contributors The original idea for this study was provided by DW and JWME. BT, AB, LS, LM, DM, SF, PK, RTM, GA, TJK, JON, DM, PH, JC, IG, CSJ were all involved in data collection. Methodology was constructed by JMGC, DW, KK and JWME. Statistical analysis was performed by JMGC, CJ and JWME. JC and JWME wrote the final manuscript and all authors were involved in its drafting.

Funding IASPIRE was funded through the Preventive Cardiology Trust and Croi, the West of Ireland Heart and Stroke Charity; with support from Amgen, AstraZeneca, Novartis, NovoNordisk, Pfizer and Sanofi Aventis. Industry funders had no role in the design, collection, analysis or reporting of the study.

Map disclaimer The depiction of boundaries on the map(s) in this article does not imply the expression of any opinion whatsoever on the part of BMJ (or any member of its group) concerning the legal status of any country, territory, jurisdiction or area or of its authorities. The map(s) are provided without any warranty of any kind, either express or implied.

Competing interests None declared.

Patient consent for publication Not required.

Ethics approval This study complies with the Declaration of Helsinki. Approval was obtained locally at each of the hospital sites by the local ethics committee: Connolly Hospital Blanchardstown, Cork University Hospital, Galway University Hospitals, Letterkenny University Hospital, Limerick University Hospital, Midlands Regional Hospital Portlaoise, Sligo University Hospital, St James's Hospital and Tallaght University Hospital. Informed consent was gained from each participant.

Provenance and peer review Not commissioned; externally peer reviewed.

Data availability statement Data may be obtained from a third party and are not publicly available. The data are not available for public use, though the authors invite requests from outside scientific groups to collaborate on analyses of the dataset.

Open access This is an open access article distributed in accordance with the Creative Commons Attribution Non Commercial (CC BY-NC 4.0) license, which permits others to distribute, remix, adapt, build upon this work non-commercially, and license their derivative works on different terms, provided the original work is properly cited, appropriate credit is given, any changes made indicated, and the use is non-commercial. See: http://creativecommons.org/licenses/by-nc/4.0/.

\section{ORCID iDs}

James MG Curneen http://orcid.org/0000-0002-6414-9803

Catriona S Jennings http://orcid.org/0000-0002-8055-3072

John William McEvoy http://orcid.org/0000-0001-6530-5479

\section{REFERENCES}

1 Moran AE, Forouzanfar MH, Roth GA, et al. Temporal trends in ischemic heart disease mortality in 21 world regions, 1980 to 2010: the global burden of disease 2010 study. Circulation 2014;129:1483-92.

2 Roth GA, Mensah GA, Johnson CO, et al. Global burden of cardiovascular diseases and risk factors, 1990-2019: update from the GBD 2019 study. J Am Coll Cardiol 2020;76:2982-3021.

3 Wright RS, Anderson JL, Adams CD, et al. 2011 ACCF/AHA focused update of the guidelines for the management of patients with unstable Angina/Non-ST-Elevation myocardial infarction (updating the 2007 guideline): a report of the American College of cardiology Foundation/American heart association Task force on practice guidelines developed in collaboration with the American College of emergency physicians, Society for cardiovascular angiography and interventions, and society of thoracic surgeons. J Am Coll Cardiol 2011;57:1920-59.

4 Smith SC, Benjamin EJ, Bonow RO, et al. AHA/ACCF secondary prevention and risk reduction therapy for patients with coronary and other atherosclerotic vascular disease: 2011 update. Circulation 2011:124:2458-73

5 Anderson L, Oldridge N, Thompson DR. Exercise-Based cardiac rehabilitation for coronary heart disease: cochrane systematic review and meta-analysis 2016:67:1-12.

6 van Halewijn G, Deckers J, Tay HY, et al. Lessons from contemporary trials of cardiovascular prevention and rehabilitation: a systematic review and meta-analysis. Int J Cardiol 2017;232:294-303.

7 Eijsvogels TMH, Maessen MFH, Bakker EA, et al. Association of cardiac rehabilitation with all-cause mortality among patients with cardiovascular disease in the Netherlands. JAMA Netw Open 2020;3:e2011686.

8 Piepoli MF, Hoes AW, Agewall S, et al. 2016 European Guidelines on cardiovascular disease prevention in clinical practice: The Sixth Joint Task Force of the European Society of Cardiology and Other Societies on Cardiovascular Disease Prevention in Clinical Practice (constituted by representatives of 10 societies and by invited experts)Developed with the special contribution of the European Association for Cardiovascular Prevention \& Rehabilitation (EACPR). Eur Heart J 2016;37:2315-81.

9 Ambrosetti M, Abreu A, Corra U. Secondary prevention through comprehensive cardiovascular rehabilitation: from knowledge to implementation. 2020 update. A position paper from the secondary prevention and rehabilitation section of the European association of preventive cardiology. Eur J Prev Cardiol 2020:2047487320913379 (published Online First: 2020/04/01).

10 Knuuti J, Wijns W, Saraste A, et al. 2019 ESC guidelines for the diagnosis and management of chronic coronary syndromes. Eur Heart J 2020;41:407-77.

11 Kotseva K, De Backer G, De Bacquer D, et al. Lifestyle and impact on cardiovascular risk factor control in coronary patients across 27 countries: results from the European Society of cardiology ESCEORP EUROASPIRE V registry. Eur J Prev Cardiol 2019;26:824-35.

12 Mathews R, Wang W, Kaltenbach LA, et al. Hospital variation in adherence rates to secondary prevention medications and the implications on quality. Circulation 2018;137:2128-38.

13 Wang TY, Dai D, Hernandez AF, et al. The importance of consistent, high-quality acute myocardial infarction and heart failure care results from the American heart association's get with the guidelines program. J Am Coll Cardiol 2011;58:637-44.

14 Middleton ET, Morice AH. Breath carbon monoxide as an indication of smoking habit. Chest 2000;117:758-63.

15 Stone NJ, Robinson JG, Lichtenstein AH, et al. 2013 ACC/ AHA guideline on the treatment of blood cholesterol to reduce atherosclerotic cardiovascular risk in adults. Circulation 2014;129:S1-45.

16 Friedewald WT, Levy RI, Fredrickson DS. Estimation of the concentration of low-density lipoprotein cholesterol in plasma, without use of the preparative ultracentrifuge. Clin Chem 1972;18:499-502.

17 Ferrières J, Lautsch D, Ambegaonkar BM, et al. Use of guidelinerecommended management in established coronary heart disease in the observational DYSIS II study. Int J Cardiol 2018;270:21-7.

18 Ferrari R, Ford I, Greenlaw N, et al. Geographical variations in the prevalence and management of cardiovascular risk factors in outpatients with CAD: data from the contemporary clarify registry. Eur J Prev Cardiol 2015;22:1056-65.

19 Cooney M, Reiner Z, Sheu W, et al. SURF - SUrvey of Risk Factor management: first report of an international audit. Eur J Prev Cardiol 2014;21:813-22. 